\title{
EL TEXTO COMO PALIMPSESTO. REFLEXIONES EN TORNO A LA LECTURA LITERARIA
}

\author{
Germán Osvaldo Prósperi \\ Universidad Nacional de La Plata (Argentina) \\ gerprosperi@hotmail.com
}

\section{INTRODUCCIÓN}

Este trabajo pretende ofrecer una respuesta posible, o los esbozos de una respuesta posible, a la pregunta "¿qué significa leer un texto literario?" La hipótesis que quisiéramos proponer es que en toda lectura literaria intervienen al menos dos textos. Por un lado, el texto efectivamente escrito, es decir la escritura impresa sobre el papel (o sobre otro soporte: pantalla, plástico, etc.) que vemos con nuestros ojos; por otro lado, un segundo texto imperceptible, invisible, superpuesto, de alguna manera, al primero. Por un lado,

1 El problema de la lectura literaria ha sido abordado sobre todo por la Rezeptionsästhetik. Los dos textos fundamentales (o paradigmáticos) en esta perspectiva, sobre todo por el impacto que provocaron en el momento de su aparición, son Literaturgeschichte als Provokation der Literaturwissenschaft de Hans R. Jauss y Die Appellstruktur der Texte de Wolfgang Iser, de 1967 y 1970, respectivamente. El mismo Jauss, por otra parte, hace referencia a ambos ensayos en el prólogo a Ästhetische Erfahrung und literarische Hermeneutik (cfr. Experiencia estética y hermenéutica literaria 15). En las páginas que siguen retomaremos algunas tesis propuestas por estos autores pero también desarrollaremos, no siempre a partir de ellas, puntos de vista propios. La categoría de palimpsesto, como veremos, nos permitirá abordar algunas cuestiones señaladas por los teóricos de la escuela de Constanza desde otra perspectiva. Al igual que esta corriente teórica, nosotros enfatizaremos también el rol del lector. Como sostiene Iser en The Act of Reading: “...el texto sólo puede tener un sentido cuando es leído" (20). En los casos en los que retomemos nociones propias de la estética de la recepción o que consideremos que algún aspecto de nuestro análisis se vincula con estas teorías (o con otros análisis teóricos, por ejemplo los de Umberto Eco o los de Roger Chartier, por mencionar solo dos nombres célebres), lo indicaremos en notas al pie. Para un panorama general de la estética de la recepción, cfr. Ortiz de Urbina 1999 y Holub 1995. El libro editado por Rainer Warning bajo el título Estética de la recepción (1989), además, ofrece una selección de artículos imprescindibles para comprender los aspectos fundamentales de esta corriente filosófica. 
entonces, lo que podríamos llamar un texto actual $^{2}$, perteneciente al registro de lo visible; por otro lado, un texto virtual, perteneciente al registro de lo invisible ${ }^{3}$. Nadie duda, por supuesto, de la existencia del primer texto, el que efectivamente leemos cuando seguimos con la mirada la secuencia de palabras dispuestas según un orden predeterminado. El problema surge cuando intentamos aprehender el segundo texto, el invisible, el que no cae bajo el poder de nuestros ojos. En este trabajo intentaremos explicar cuál es el estatuto de este segundo texto enigmático y, al mismo tiempo, la relación que mantiene con el texto visible. En esa relación, en la oscilación de un texto a otro, se encuentra, creemos, lo más propio de la lectura literaria ${ }^{4}$.

\section{I - EL TEXTO COMO PALIMPSESTO}

Los antiguos utilizaban el término $\pi \alpha \lambda i ́ \mu \psi \eta \sigma \tau o v$ (palimpsesto), que significa grabado de nuevo, para designar aquellos pergaminos en los que se borraba una escritura antigua

2 Sobre el aspecto actual de la lectura literaria, es decir, sobre el proceso de actualización implícito en toda recepción estética, cfr. Mukarovsky 1988. En la perspectiva social adoptada por Mukarovsky en varios de los ensayos que componen Escritos sobre estética y semiótica del arte, la función estética, a diferencia de otras funciones prácticas del lenguaje, implica una actualización por parte del receptor. Por otro lado, Paul Válery, un referente central para los teóricos de la Rezeptionsästhetik, sostiene, en la primera lección del Cours de poétique: “...la obra del espíritu no existe más que en acto. Fuera de este acto, lo que queda no es más que un objeto que no ofrece ninguna relación particular con el espíritu" (Válery 306). Como veremos, en el caso de Henri Bergson, el espíritu será identificado precisamente con lo virtual, y no con lo actual, como en Válery. Hans Jauss, además, en el célebre ensayo Literaturgeschichte als Provokation der Literaturwissenschaft, define la lectura literaria y al proceso de recepción estética como una actualización por parte del lector: "La historia de la literatura es un proceso de recepción y de producción estéticas, que se efectúa en la actualización de textos literarios por parte del lector..." (Pour une esthétique de la réception 48). Una idea similar encontramos en Umberto Eco: "Un texto, tal como aparece en su superficie (o manifestación) lingüística, representa una cadena de artificios expresivos que el destinatario debe actualizar" (Lector in fabula 73). Lo mismo en Wolfgang Iser: “... [la concreción del sentido] existe sólo como una realidad potencial - requiere de un sujeto (i.e. del lector) para que lo potencial sea actualizado" (The Act of Reading 66).

Ambos conceptos, el de actual y el de virtual, serán explicados en detalle en la sección III. Para una perspectiva ontológica de la distinción visible/invisible, cfr. MerleauPonty 1964.

En este artículo nos centraremos particularmente en la lectura (y consecuentemente también en la escritura) literaria, aunque no están excluidas a priori otras prácticas discursivas como la filosofía o la historia. Sin embargo, creemos que las categorías propuestas aquí para pensar la lectura se ajustan con mayor comodidad, como se verá, al caso de la literatura. Cfr., para una explicación más detallada de por qué abordamos el caso específico de la lectura literaria, la nota 32 de este escrito. 
y se transcribía, sobre ese mismo soporte, una nueva escritura ${ }^{5}$ " "Solemos denominar «palimpsestos» a los códices escritos sobre folios de pergamino cuya primera escritura se eliminó mediante lavado o raspado para poder transcribir sobre ese mismo pergamino un segundo texto" (Escobar 16). Nos interesa la figura del palimpsesto porque designa un texto en el que conviven al menos dos escrituras diversas: la scriptio inferior, la más antigua, y la scriptio superior, la más reciente ${ }^{6}$. Según los latinos, la scriptio inferior correspondía al texto antiguo, llamado codex antiquior; la scriptio superior, por su parte, al texto más reciente, conocido como codex rescriptus o codex recentior (cfr. Crisci 44-47). Como bien ha mostrado Elias Avery Lowe en el segundo volumen de

5 En un texto sugerente, cuyo título precisamente es Inscribir y borrar. Cultura escrita y literatura (siglos XI-XVIII), Roger Chartier analiza estas dos prácticas, la inscripción y la borradura, desde una perspectiva más amplia que el caso específico del palimpsesto. Según Chartier, la escritura pretendía, en los siglos considerados por el autor, conjurar el temor a la pérdida. Por eso motivo, los escritos funcionaban como receptáculos de aquello que no debía ser olvidado. Pero al mismo tiempo, se volvió preciso controlar la proliferación desmedida de textos, razón por la cual se recurrió también y simultáneamente a la práctica de borrar. En este artículo, sin embargo, nosotros circunscribiremos estas dos prácticas, la inscripción y la borradura, al caso específico del palimpsesto, aunque considerándolo como el paradigma de todo texto literario. Sobre la inscripción y la borradura, cfr. Chartier 2006.

${ }_{6} \quad$ En Palimpsestes. La littérature au second degré, Gérard Genette ha profundizado la relación hipertextual que existe en todo texto. La hipertextualidad se define como una "... relación que une un texto B (que llamaré hipertexto) a un texto A (al que llamaré hipotexto) en el que se injerta de una manera que no es la del comentario" (14). Como resulta evidente, el concepto de hipotexto de Genette traduce la scriptio inferior de los latinos, así como el concepto de hipertexto la scriptio superior. El hipertexto, por su parte, designa, según Genette, "...todo texto derivado de un texto anterior por transformación (...) o por (...) imitación" (17). Un ejemplo de hipertextualidad, siempre en la perspectiva de Genette, es la Eneida de Virgilio o el Ulysses de Joyce, obras que funcionan como hipertextos de la Odisea homérica, la cual funciona como hipotexto. Como veremos más adelante, nuestra categoría de palimpsesto difiere de la hipertextualidad de Genette. La scriptio inferior, el hipotexto, no es un texto cronológicamente anterior a la scriptio superior, al hipertexto. Ni siquiera es una obra efectivamente existente. En nuestro caso, como explicaremos en las páginas que siguen, ambas escrituras son coextensivas y simultáneas. Es verdad que hacia el final de Palimpsestes, así como en el capítulo II, Genette habla de una auto-hipertextualidad, es decir de un "... estado redaccional [que] funciona como un hipertexto en relación al precedente, y como un hipotexto en relación al siguiente" (491). Por tal motivo, concluye Genette, “...la génesis de un texto es un asunto de auto-hipertextualidad" (cfr. ibíd.). De todas formas, a pesar de hablar de una auto-hipertextualidad, Genette tiende a pensar la relación entre la scriptio inferior y la scriptio superior de manera sucesiva y no, como en nuestra perspectiva, simultánea, o, por lo pronto, tiende a pensarla como una simultaneidad que remite por necesidad a un momento o texto previo. Nuestra categoría de palimpsesto, por el contrario, no se define por una sucesión temporal, sino más bien, como hemos anticipado, por una coexistencia espacial o, para decirlo con mayor precisión, por una simultaneidad temporal y por una contigüidad espacial. 
sus Palaeographical papers, la confección de palimpsestos se debía fundamentalmente a tres factores: un factor económico (alto costo de los pergaminos); un factor gráficocodigológico (grafías en desuso o de difícil lectura); un factor relativo al contenido (lenguas extranjeras o incomprensibles, textos de los cuales se disponía de varias copias, etc.) (cfr. 441-449). La práctica de utilizar códices ya escritos como soportes de una nueva escritura es interesante, además, porque revela siempre, según afirma Edoardo Crisci, “...una condición de malestar, de crisis, de desorientación cultural en relación al producto-libro..." (cfr. 43). No es casual, en este sentido, que también Crisci llegue a sostener que "...las prácticas de cancelación de la scriptio inferior [resultaban] siempre en cierta medida traumáticas..." (42). El lavado o el raspado de la escritura antigua implica, por necesidad, una cierta forma de trauma.

Según nuestra hipótesis, todo texto literario funciona como un palimpsesto, es decir como un lugar o una superficie topológica en la que coexisten por lo menos dos escrituras: una visible, la scriptio superior, y otra invisible, la scriptio inferior. Por la misma razón, si todo texto literario guarda la forma de un palimpsesto, y si la práctica del palimpsesto es siempre traumática, entonces toda escritura, todo texto literario es por necesidad traumático. Escribir, desde este punto de vista, es borrar una escritura previa, es superponer dos textos, pero al mismo tiempo, y de ahí su carácter traumático, es volver invisible el codex antiquior, la escritura inferior, para que se haga visible el codex recentior, la escritura superior. Si, como han afirmado varios pensadores contemporáneos, desde Georges Bataille a Maurice Blanchot, desde Michel Foucault a Jacques Derrida, la escritura posee una relación íntima con la muerte, es quizás porque escribir, dar a luz una escritura, supone por necesidad dar muerte a otra escritura coextensiva, aunque no más originaria. La escritura vive, pues, de su propia muerte. El texto no es sino el lugar de este encuentro decisivo, el tejido en el que se entrecruzan la vida y la muerte del lenguaje. El escritor, el textor, es el tejedor, el que hilvana, con su praxis, los hilos de la vida y de la muerte, de lo visible (la scriptio superior) y de lo invisible (la scriptio inferior $)^{7}$. Se debe matar la escritura antigua para dar vida a la nueva. De todas formas, no se trata de un proceso sucesivo, sino de una coexistencia o una simultaneidad, un poco al modo en que Xavier Bichat pensaba la relación, también contemporánea, entre la vida y la muerte ${ }^{8}$.

7 Sobre la escritura como tejido, cfr. Chartier 2006, cap. 6.

8 Este tema, como se sabe, ha sido retomado por Michel Foucault en Naissance de la clinique. La muerte, con Bichat, deja de ser ese absoluto existencial que se abre al final de una vida para clausurarla y pasa a ser, más bien, un acontecimiento coextensivo a la vida misma. "Bichat ha relativizado el concepto de muerte, haciéndolo decaer de este absoluto donde aparecía como un acontecimiento inexorable, decisivo e irrecuperable: lo ha volatilizado y repartido en la vida, bajo forma de muertes en detalle, muertes parciales, progresivas y tan lentas que se extienden incluso más allá de la muerte misma" (Foucault 147). La relación que, en nuestra perspectiva, mantienen las dos escrituras del texto entendido como palimpsesto coincide, entonces, con esta “...permeabilidad de la vida y la muerte" (cfr. Foucault 144) 
Ambos textos, ambas escrituras, son siempre heterogéneas. Sobre todo en la Antigüedad, y hasta bien entrada la Edad Media, los pergaminos utilizados como soportes de nuevas escrituras eran por lo general de origen diverso: “...con frecuencia los pergaminos revelan orígenes heterogéneos: manuscritos de diversa época, tipología, formato, dimensiones..." (Crisci 47). Tal es así que en muchos casos, como en el famoso palimpsesto de Arquímedes, se encuentran superpuestas varias escrituras ${ }^{9}$. De todas formas, por razones de comodidad, nos concentraremos en las dos escrituras que hemos distinguido hasta aquí, la inferior y la superior, teniendo en cuenta sin embargo que la más antigua, al igual que la más reciente, puede englobar escrituras en sí mismas múltiples y heterogéneas. Hemos dicho que todo texto literario es en realidad un palimpsesto. De todas formas, es preciso indicar que, a diferencia de los códices antiguos y medievales llamados efectivamente palimpsestos, en los que las dos escrituras eran, en mayor o menor medida, visibles, en el caso de los textos literarios que no entran bajo esa categoría (en su sentido tradicional) el codex antiquior, la escritura inferior, es por cierto invisible y, según una paradoja que tendremos que considerar, prácticamente inexistente. ¿Cómo hablar de un texto que, desde el punto de vista de la representación, es decir de la presentación de lo presente, no existe? ¿Cómo la lectura, y asimismo la escritura, pueden aludir a un texto que es en sí mismo irrepresentable? ¿Cómo es posible leer lo que no puede ser leído? He aquí la aporía que tendremos que resolver.

\section{II - PIERRE MENARD Y/O MIGUEL DE CERVANTES}

El palimpsesto antiguo, hemos dicho, supone la coexistencia de dos escrituras cuya heterogeneidad es, en cierta manera, manifiesta y fácilmente verificable. La escritura inferior y la superior difieren en cuanto a contenido, tipología, cronología, etc. Nuestra hipótesis, sin embargo, nos ha llevado a considerar a todo texto literario como un palimpsesto, pero por eso mismo, como un palimpsesto sumamente particular. En los textos literarios que leemos cotidianamente, la scriptio inferior, invisible y aparentemente irreal, pareciera haber desaparecido por completo o, incluso, pareciera no haber existido nunca. Es una mera apariencia, no obstante. Una apariencia provocada por la casi coincidencia de ambas escrituras. El caso paradigmático de esta forma excéntrica de palimpsesto ha sido detallado con genialidad por Jorge Luis Borges en su relato Pierre Menard, autor del

que descubre Bichat, pero también Diderot por ejemplo en Le rêve de d'Alembert, en el siglo XVIII.

9 Un escriba anónimo, en el siglo X, copió parte de la obra de Arquímedes, quien vivió en el siglo III a. C. En el siglo XII, el pergamino fue raspado y lavado, junto a otros manuscritos entre los que se incluían discursos del político ateniense Hispérides (siglo IV a. C.), un comentario de Alejandro de Afrodisia a Aristóteles y otros textos, para transcribir un texto litúrgico. 
Quijote $^{10}$. El núcleo del cuento es célebre: Pierre Menard, escritor vanguardista del siglo XX, decide componer el Quijote. No se trata de transcribirlo ni de copiarlo, sino de “... producir unas páginas que coincidieran -palabra por palabra y línea por línea- con las de Miguel de Cervantes" (Borges 446). Lo propio de Borges es, de algún modo, invertir la relación de los textos. De allí que el Quijote 'final' sea también, para Borges, una suerte de palimpsesto: "He reflexionado que es lícito ver en el Quijote 'final' una especie de palimpsesto..." (450). Sin embargo, hay un punto en el que se vuelve imposible determinar si el texto visible, legible, corresponde a Cervantes o a Menard. “¿Confesaré que suelo imaginar que la terminó [Borges se refiere a la empresa de escribir, en el siglo XX, el Quijote] y que leo el Quijote -todo el Quijote- como si lo hubiera pensado Menard?" (447). De algún modo, las dos escrituras, en el punto de su máxima tensión, coinciden, pero esa coincidencia, lejos de identificarlas o sintetizarlas en un único texto, manifiesta más bien su inexorable lejanía. Borges lo dice con claridad: "El texto de Cervantes y el de Menard son verbalmente idénticos, pero el segundo es casi infinitamente más rico" (449) ${ }^{11}$. Ambos textos, el codex antiquior de Cervantes, la scriptio inferior, y el codex recentior de Menard, la scriptio superior, coinciden en un plano verbal, visible; difieren, sin embargo, y difieren infinitamente, en otro plano, no representativo, irrepresentable ${ }^{12}$. El punto de mayor coincidencia y, a la vez, de mayor diferencia y tensión entre ambos textos se vuelve explícito cuando Borges coteja dos frases concretas, una de Cervantes, la otra de Menard. Dada la importancia del pasaje, lo citamos in extenso:

Es una revelación cotejar el Don Quijote de Menard con el de Cervantes. Éste, por ejemplo, escribió (Don Quijote, primera parte, noveno capítulo):

...la verdad, cuya madre es la historia, émula del tiempo, depósito de las acciones, testigo de lo pasado, ejemplo y aviso de lo presente, advertencia de lo por venir.

Redactada en el siglo diecisiete, redactada por el 'ingenio lego' Cervantes, esa enumeración es un mero elogio retórico de la historia. Menard, en cambio, escribe:

10 Cfr. particularmente el epílogo a La main de l'auteur et l'esprit de l'imprimeur de Roger Chartier.

${ }_{11}$ No es casual que Gilles Deleuze, en el prólogo a Différence et répétiton (1968), pueda citar precisamente este pasaje de Borges, inmediatamente después de afirmar que "... la repetición más exacta, la más estricta, tiene como correlato el máximo de diferencia" (5).

12 Como resulta evidente, cuando utilizamos las expresiones codex antiquior o scriptio inferior para referirnos al Quijote de Cervantes, así como las expresiones codex recentior o scriptio superior para el Quijote de Menard, las estamos interpretando en su sentido habitual, según la concepción tardo-antigua del palimpsesto, retomada luego por Genette. El relato de Borges, sin embargo, nos permite esbozar otra caracterización, en cierto sentido excéntrica, de la figura del palimpsesto. Dado que en el caso del Pierre Menard, como hemos visto, ambas escrituras coinciden, aunque solo para diferir, estamos obligados a pensar de otra manera la distinción entre la scriptio inferior y la scriptio superior. 
...la verdad, cuya madre es la historia, émula del tiempo, depósito de las acciones, testigo de lo pasado, ejemplo y aviso de lo presente, advertencia de lo por venir (449).

Como puede observarse, las dos frases son verbalmente idénticas; sin embargo, como dice Borges, la de Menard es infinitamente más rica ${ }^{13}$. De allí que Borges pueda hablar del vívido “...contraste de los estilos" (cfr. 449) de ambos autores. Mucho más arcaizante y afectado el de Menard; espontáneo el de Cervantes, que maneja con desenfado el español de su época. Ambas citas, la de Cervantes y la de Menard, llevan al extremo la tensión entre las dos escrituras que conforman todo texto literario. Pero lo interesante no concierne solo a la escritura, a la praxis escritural. Si bien la mayor parte de los comentarios que ha recibido este relato de Borges lo interpretan como una reflexión sobre la escritura, lo cierto es que el mismo Borges, hacia el final, se encarga de extrapolar el núcleo del relato hacia el problema de la lectura. "Menard (acaso sin saberlo) ha enriquecido mediante una técnica nueva el arte detenido y rudimentario de la lectura: la técnica del anacronismo deliberado y de las atribuciones erróneas" (450). Es posible que Pierre Menard, autor del Quijote, a fin de cuentas, no sea sino una extraordinaria reflexión sobre la lectura. Leer, en tal caso, no significaría solo recorrer con la mirada el texto de Menard $o$ el de Cervantes, la scripto inferior o la scripto superior, sino más bien hacer coexistir ambos textos, el de Menard y el de Cervantes, las dos escrituras, la inferior $y$ la superior. Leer, en consecuencia, no significaría privilegiar una escritura sobre la otra, sino volver perceptible sus tensiones y sus discrepancias ${ }^{14}$. Y acaso no se lea, al menos

13 Umberto Eco, en Lector in fabula, explica la coincidencia gráfica entre los "dos" Quijotes como un accidente circunstancial: “...el Quijote de Pierre Menard es muy distinto del de Cervantes, con el que accidentalmente concuerda palabra por palabra..." (86). Arthur C. Danto, por su parte, en The Transfiguration of the Commonplace, explica la relación que poseen estas dos escrituras, estos dos textos, como una "indiscernibilidad gráfica" (cfr. Danto 35). Esta indiscernibilidad gráfica, sin embargo, solo revela diferencias irreductibles entre la scriptio inferior y la scriptio superior. Hay ciertos elementos o propiedades en toda obra de arte, sostiene Danto, que no son visibles por el ojo. Respecto a los textos de Cervantes y de Menard, por ejemplo, dice: "Tienen sólo en común aquellas propiedades que el ojo como tal puede identificar. (...) El ejemplo de Borges tiene el efecto filosófico de desviar nuestro ojo de la superficie de las cosas, y de obligarnos a pensar dónde, si no es en la superficie, se encuentra la diferencia entre obras distintas" (35). En este sentido, también en Danto aparece una dimensión invisible como parte esencial y constitutiva de todo texto literario. Sin embargo, si bien no es este el lugar para extendernos sobre esta cuestión, es preciso indicar que nuestra conceptualización del texto invisible, de la scriptio inferior, si bien no excluye a la de Danto, se orienta en otra dirección. Para un panorama introductorio a la concepción estética de Danto, cfr. Andina 2010.

14 Esta convivencia de dos escrituras o de dos textos diversos, la scriptio inferior y la scriptio superior, se acerca, en cierto sentido, a la idea de "fusión de horizontes" planteada por Hans-Georg Gadamer. En Verdad y método, por cierto, leemos: "El horizonte del presente no se forma pues al margen del pasado. Ni existe un horizonte del presente en sí mismo ni hay horizontes históricos que hubiera que ganar. Comprender es siempre el proceso de fusión de 
en un sentido literario, ni el codex antiquior ni el codex recentior, ni el texto actual ni el texto virtual, ni el Quijote de Menard ni el de Cervantes, sino más bien una suerte de tercer texto intermedio, casi imposible, un límite, un pliegue, un inter-texto ${ }^{15}$.

\section{III - EL TEXTO ACTUAL Y EL TEXTO VIRTUAL}

¿Cómo debemos entender este tercer texto, este texto intermedio o inter-texto que al parecer constituye el "objeto" más propio de la lectura literaria? En las páginas precedentes hemos sugerido, casi de pasada, que el codex antiquior funcionaba como una suerte de texto virtual, mientras que el codex recentior lo hacía como un texto actual. Ahora bien, para comprender en profundidad qué entendemos por "palimpsesto", $\mathrm{y}$, consecuentemente, para comprender qué entendemos por "lectura literaria", será preciso que expliquemos el sentido de estos dos términos, actual y virtual, los cuales no han sido hasta el momento

estos presuntos 'horizontes para sí mismos"' (Gadamer 376-377). Esta idea, por supuesto, ha sido retomada por Hans Jauss para pensar la recepción estética (cfr., por ejemplo, el apartado IX de Literaturgeschichte als Provokation der Literaturwissenschaft, así como también Pour une esthétique de la réception 259-260). Jean Starobinski, en el prefacio a Pour une esthétique de la réception, una recopilación de ensayos de Jauss en lengua francesa, lo dice con claridad: "Para progresar, la reflexión hermenéutica debe aplicarse siempre a sacar conscientemente las consecuencias de la tensión que interviene entre el horizonte del presente y el texto del pasado. Nosotros no podemos más que intentar ir a su encuentro, con los intereses, la cultura -brevemente, el horizonte- que son los nuestros. Es lo que Jauss, después de Gadamer, llama la "fusión de horizontes"” (Starobinsky 15-16). Se puede pensar, a partir de estos párrafos, que la lectura supone la relación entre dos horizontes cronológicamente diversos, el del autor y el del lector, el horizonte pasado y el horizonte presente. Sin embargo, en nuestra perspectiva, y también -creemos- en la hermenéutica de Gadamer y Jauss, el horizonte pasado coexiste, como veremos un poco más adelante, con el horizonte presente. El texto, en este sentido, es el espacio potencial o virtual del pasado que coexiste con el presente. Para que esta coexistencia se actualice es preciso, por supuesto, que el texto sea leído. Como sostiene Wolfgang Iser en el prefacio a The Act of Reading: “...el texto representa un efecto potencial que es realizado en el proceso de lectura" (ix). Sin embargo, estas dos dimensiones, la presente y la pasada, en nuestra perspectiva, son ya partes constitutivas del texto. Esta coexistencia del pasado y el presente será explicada con mayor detalle en la sección siguiente de este artículo.

15 Con la noción de intertextualidad, Genette parece acercarse a nuestra perspectiva, según la cual ambos textos, el codex antiquior y el codex recentior, son instancias contemporáneas y coexistentes. En efecto, la intertextualidad es definida por Genette como “... una relación de copresencia entre dos o más textos, es decir, eidéticamente y frecuentemente, como la presencia efectiva de un texto en otro" (Palimpsestos 10). Sin embargo, cuando menciona algunas de las figuras de la intertextualidad (la cita, el plagio y la alusión), se vuelve claro que ninguna de ellas coincide con nuestra idea de inter-texto. El codex recentior, la scriptio inferior, en nuestro caso, no es remisible a (ni identificable con) ningún texto efectivo o materialmente "existente". 
desarrollados. Con este propósito, deberemos hacer primeramente un rodeo por la filosofía de Henri Bergson, concentrándonos en particular en Matière et mémoire, ya que es en este texto donde ambas categorías son explicitadas. Nuestro objetivo, por supuesto, es aclarar el estatuto de ambos textos, el actual y el virtual, así como su relación específica.

\section{III.1 - LA MATERIA y LA MEMORIA EN HenRi Bergson}

La pareja conceptual actual/virtual, como indicamos, remite a la filosofía de Bergson. En Matière et mémoire, Bergson identifica al pasado con lo virtual y al presente con lo actual. Una de las tesis más importantes de este libro extraordinario es que entre la materia y la percepción no hay una diferencia de naturaleza sino de grado; en cambio, entre la materia y la memoria, entre lo actual y lo virtual, hay "una diferencia radical de naturaleza" (cfr. Bergson 141). La percepción y la acción son lo propio del presente viviente, es decir de lo actual; el recuerdo, por el contrario, es lo propio del pasado, es decir de lo virtual. Ahora bien, entre los movimientos recibidos por el sistema sensoriomotor y los que intentan preparar la reacción de mi cuerpo se introduce una distancia (écart) que genera una indeterminación y una respuesta imprevista. Esta distancia no es solo un intervalo espacial, sino sobre todo un delay, una pausa, un deslizamiento del tiempo entre los dos movimientos: el centrípeto que llega al cerebro desde los sentidos y el centrífugo que parte de él hacia los centros periféricos que realizan el movimiento de respuesta. En este delay cerebral, en este intervalo que se produce entre el estímulo y la respuesta, la memoria, lo virtual, dice Bergson, se inserta en la materia, en lo actual; el tiempo, el espíritu, se introducen en el cuerpo: “...esta memoria espera simplemente que una fisura se produzca entre la impresión actual y el movimiento concomitante para deslizar allí sus imágenes" (57). La memoria ejerce una presión sobre la percepción, intercala el pasado en el presente, el recuerdo en la sensación, el tiempo en el espacio o el espíritu en la materia. De algún modo, en el punto de contacto entre la materia y la memoria, en el límite o el pliegue entre la percepción y el recuerdo, se ubica la imaginación. Recordar es actualizar un contenido pasado. Para esto, es preciso que ese recuerdo puro, plenamente virtual e impasible, se encarne en una imagen. Esa es la función de la imaginación.

\section{III.2 - ENTRE LO ACTUAL Y LO VIRTUAL}

Intentemos resumir, ahora, los puntos que hemos individuado en el pensamiento bergsoniano tal como aparece en Matière et mémoire: 1) lo actual es el presente viviente, el aspecto sensorio-motriz de mi existencia, el cuerpo como centro de acción, es decir, como centro perceptivo; 2) lo virtual es el pasado, el aspecto inactivo de mi existencia, el espíritu como memoria, como tiempo, como $\mathrm{Ser}^{16} ; 3$ ) entre los movimientos recibidos

16 Recordemos que la memoria, para Gilles Deleuze, tal como aparece en Bergson, no supone una instancia psicológica o subjetiva que la origine y la funde; más bien es a la inversa, la memoria psicológica, el sujeto, surge como un precipitado de una memoria ontológica: 
por el sistema sensorio-motor y los que intentan preparar la reacción de mi cuerpo se produce una distancia (écart), una fisura o una pausa que hace posible la inserción de lo virtual, de la memoria o el pasado, en lo actual, en el presente; 4) para que un recuerdo pueda actualizarse e ingresar ${ }^{17}$ en el presente, es preciso que se encarne en una imagen, función que realiza la imaginación.

Ahora bien, ¿de qué nos sirven estas determinaciones para nuestro análisis del palimpsesto y de la lectura literaria? En todo palimpsesto, como hemos dicho, intervienen al menos dos textos. En principio, el codex recentior o la scriptio superior deben ser entendidos a partir del concepto de actual, así como el codex antiquior o la scriptio inferior a partir del concepto de virtual. El codex recentior designa el texto efectivamente escrito, el texto que percibimos con nuestros ojos. Por eso lo actual, en Bergson, se identifica con el mundo de la percepción. Y por eso la percepción, también, es siempre presente. Bajo esta primera determinación, la lectura del texto actual, del codex recentior, es por necesidad presente ${ }^{18}$. Pero además de esta escritura actual, de esta scriptio superior, hemos

"Nosotros nos reubicamos primero, dice Bergson, en el pasado en general: lo que así describe es el salto en la ontología. Saltamos realmente en el ser, en el ser en sí, en el ser en sí del pasado. Se trata de salir de la psicología, se trata de una Memoria inmemorial u ontológica. Es sólo después, una vez que hemos dado el salto, que el recuerdo va a tomar poco a poco una existencia psicológica: de virtual pasa al estado actual..." (Le bergsonisme 52).

17 El concepto de ingresión (ingression) pertenece a Alfred North Whitehead. Según la filosofía de Whitehead, también llamada philosophy of organism, los "objetos eternos", que podríamos comparar (sin identificarlos) con los contenidos virtuales de Bergson, se introducen en las "entidades actuales" a través de un proceso denominado "ingresión" [ingression]. En Process and Reality, Whitehead, que no por casualidad se había interesado en la filosofía de Bergson, explica que el mundo actual es un proceso, y que dicho proceso no es sino el devenir de las entidades actuales. Según esta metafísica del acontecimiento, los objetos eternos, a diferencia de las ocasiones o entidades actuales, son potencialidades puras que pueden ingresar eventualmente en el devenir actual del mundo y realizarse. En la sección II del segundo capítulo de Process and Reality, Whitehead explica algunas de sus categorías centrales. La proposición VII de las Categories of Explanation, sin ir más lejos, postula: "Que un objeto eterno puede ser descripto sólo en función de su potencialidad de 'ingresión' en el devenir de las entidades actuales; que su análisis sólo revela otros objetos eternos. Es un puro potencial. El término 'ingresión' se refiere al modo particular por el cual la potencialidad de un objeto eterno es realizada en una entidad actual particular, contribuyendo a la determinación de dicha entidad actual" (23). Es preciso notar que Iser cita a Whitehead en The Act of Reading para explicar el proceso de lectura. Luego de transcribir un pasaje de Science and the Modern World, escribe lo siguiente: “...existe un proceso continuo de actualización, y por lo tanto la lectura misma sucede como un acontecimiento, en el sentido en que lo que leemos asume el carácter de una situación abierta, al mismo tiempo concreta y fluida" (68).

18 Esta tesis se ajusta perfectamente a la concepción de la lectura propuesta por gran parte de los teóricos de la estética de la recepción, para quienes leer no es sino actualizar un texto escrito. La lectura, en este sentido, se presenta como un proceso de actualización. Cfr. la nota 2 de este artículo. 
indicado que existe otro texto virtual, coextensivo al texto empíricamente verificable. Esta segunda escritura, esta scriptio inferior, no resulta ya percibida directamente, puesto que no forma parte del presente, sino del pasado y de la memoria ${ }^{19}$. Pero aquí hay que ser cautelosos y no creer que, por ser pasada, la escritura virtual antecede cronológicamente a la escritura actual, y que por lo tanto la relación entre ambas escrituras se funda en una sucesión temporal ${ }^{20}$. Por el contrario, Bergson, en Matière et mémoire, sostiene que el presente no es sino "la síntesis actual de todos nuestros estados pasados" (cfr. 87) o, lo que viene a ser lo mismo, que el pasado existe de "forma condensada" (cfr. ibíd.) en nuestro presente ${ }^{21}$. Deleuze lo dice con claridad en su texto de 1966 sobre Bergson:

19 Sobre la relación entre la escritura, el texto y la memoria, cfr. Chartier 2015 cap. $\mathrm{X}$.

20 Muchas veces se suele interpretar de una manera errónea la idea de "fusión de horizontes" planteada por la hermenéutica de Gadamer y, a partir de él, por Jauss. En nuestra perspectiva, la cual se basa fundamentalmente en el pensamiento de Bergson, el pasado, lo virtual, coexiste en el mismo texto. En este sentido, la distinción actual/virtual no posee una naturaleza meramente cronológica, como pareciera inferirse de algunas de las tesis propuestas por la corriente hermenéutica. El texto es a la vez actual y virtual, lo mismo que el proceso de lectura. Ya el texto, en sí mismo, posee una dimensión actual representada por las letras escritas, y otra dimensión virtual que, incluso sin ser actualizada por la lectura, es no obstante real. Por eso Bergson distingue entre los recuerdos imágenes y los recuerdos puros. Ambos son virtuales, pero mientras que los primeros son susceptibles de ser actualizados, los segundos no lo son necesariamente. Gilles Deleuze utiliza una frase de Proust para referirse a estos recuerdos puros: "reales sin ser actuales, ideales sin ser abstractos" (Le bergsonisme 99). Wolfgang Iser, por su parte, parece sugerir una idea similar, aunque desde otra perspectiva, cuando escribe: “...el potencial total [de sentidos de un texto] no puede ser nunca colmado en el proceso de lectura..." (The Act of Reading 22). Resulta problemático establecer con precisión el estatuto ontológico del texto virtual o potencial. Según las tesis de Bergson y de Deleuze, lo virtual es real sin ser actual. Desde una óptica similar, Whitehead pareciera llegar a la misma conclusión respecto a la existencia o realidad de los objetos eternos (puras potencialidades, entidades conceptuales no actuales). Incluso sin ser actualizados en una ocasión de experiencia, los objetos eternos existen en el espíritu de Dios, en su naturaleza primordial. Dios ordena las potencialidades conceptuales y las dispone para su ingresión en las ocasiones actuales. “...toda actualidad que se realiza en el mundo preexiste, a título de potencialidad, en el espíritu primordial de Dios" (Parmentier 344). El problema del estatuto ontológico de lo virtual o potencial, por supuesto, excede el marco de este artículo. Cfr., en este sentido, Parmentier caps. VIII y IX.

$21 \quad$ Lo cual significaría, para nosotros, que el codex recentior es el extremo actual del codex antiquior, su punto más contraído. De todas formas, no nos adentraremos, como ya hemos indicado en la nota previa, en los arduos problemas que han suscitado, y suscitan aún, ciertos aspectos de la relación entre lo actual y lo virtual. Simplemente, nos contentamos con dejarlo planteado, y con retener, al mismo tiempo, algunos elementos de estas categorías en la medida en que nos resultan oportunos para pensar nuestro concepto de palimpsesto. 
El pasado y el presente no designan dos momentos sucesivos, sino dos elementos que coexisten, uno que es el presente, y que no deja de pasar, el otro, que es el pasado, y que no deja de ser, pero por el cual pasan todos los presentes. Es en este sentido que hay un pasado puro, una suerte de pasado en general: el pasado no sigue al presente, sino al contrario, es supuesto por él como la condición pura sin la cual no pasaría. En otros términos, cada presente reenvía a sí mismo como pasado (54-55).

Si bien lo actual y lo virtual, el codex recentior y el codex antiquior, difieren por naturaleza, existen no obstante en una relación mutua de imbricación o coalescencia. A esta relación entre lo actual y lo virtual, es decir entre el presente y el pasado, se refiere también Deleuze, en Le bergsonisme, con la expresión paradoja de la contemporaneidad (cfr. 57). Esta expresión avanzada por Deleuze para explicar uno de los aspectos más problemáticos e incomprendidos del bergsonismo nos resulta útil y pertinente en la medida en que nos permite abordar la relación entre ambos códices y ambas escrituras no ya como una relación de sucesión, sino de simultaneidad y coexistencia. Para pensar esta relación, y en consecuencia para poder elaborar nuestra categoría de palimpsesto, es preciso tener en cuenta al menos cuatro aspectos del pensamiento de Bergson: 1) el codex recentior designa el texto actual, así como el codex antiquior el texto virtual; 2) ambos textos difieren por naturaleza, pero sin embargo existen (o, más bien, coexisten) bajo una relación de coalescencia o de imbricación inmanente; 3) por las fallas o grietas del texto actual se insinúa (o inserta) el texto virtual; 4) el pliegue de ambos textos, el intervalo entre el texto actual y el virtual, el inter-texto es el espacio topológico de la imaginación ${ }^{22}$.

Lo propio de la lectura literaria, hemos dicho, concierne precisamente a este intervalo o inter-texto, es decir a la fisura que permite la oscilación entre la escritura virtual y la escritura actual, entre el codex antiquior y el codex recentior ${ }^{23}$. Así como lo propio del

22 En el capítulo 6 de The Act of Reading. A Theory of Aesthetic Response, Wolfgang Iser señala la importancia que posee la imaginación, es decir la facultad capaz de crear imágenes mentales, a la hora de comprender la lectura de un texto literario. No solo la comprensión y el sentido del texto dependen de esta facultad, a la que Kant había calificado de "misteriosa", sino que ella indica el lugar (o no-lugar) en el que el mundo del texto y el mundo del lector se articulan. "Resulta extremadamente difícil decir dónde terminan las señales y dónde comienza la imaginación del lector en este proceso de proyección" (135); y un poco más tarde: "Lo que el lenguaje dice es trascendido por lo que encubre, y lo que encubre representa su verdadero significado. El sentido de la obra literaria permanece vinculado a lo que dice el texto impreso, pero requiere de la imaginación creativa del lector para concretizarlo" (142).

23 Es importante tener presente, para comprender la relación entre el texto actual y el texto virtual, el concepto de "indeterminación" que Iser retoma de Ingarden. Este concepto alude a la dimensión no formulada en el texto, a lo que Iser denomina el "texto no escrito" (cfr. 182), el cual resulta fundamental, sin embargo, para la concreción del sentido de la obra literaria. Existen ciertos puntos blancos o lagunas en el texto escrito que deben ser completadas por el lector. "Ellos [los puntos blancos] son las junturas invisibles del texto, y en la medida en que ligan los esquemas con las perspectivas textuales, producen simultáneamente actos 
cerebro humano, sostiene Bergson, es generar una suerte de delay o fisura que permite la inserción o "ingresión" del pasado en el presente, así también la estructura del codex recentior está recorrida por fisuras y fallas por las que se insinúa el codex antiquior ${ }^{24}$. El intervalo entre ambos códices es el lugar de la oscilación misma. En este pliegue difícil de aprehender, se efectúa la economía de ambas escrituras, el intercambio de fuerzas entre los dos textos del palimpsesto. Economía que se define a través de dos movimientos pendulares: uno que va de lo virtual a lo actual (y que Bergson identifica con la reminiscencia); otro que va de lo actual a lo virtual (y que Bergson identifica con el olvido). Estos dos movimientos, de contracción (hacia lo actual) y de dilatación (hacia lo virtual), vale la pena aclarar, no suponen ningún dualismo, sino más bien una impregnación de dos escrituras que constituyen un mismo tejido, una misma experiencia. Lo esencial no son tanto los términos de la relación, el codex antiquior o el codex recentior, sino más bien, como sugeríamos a partir del Pierre Menard de Borges, su interconexión, su pliegue o su intervalo. No ya este o aquel texto, sino éste Y aquél, Cervantes Y Menard. Por esta razón Claire Parnet, en sus Dialogues con Gilles Deleuze, ha podido afirmar que la única manera de deconstruir los dualismos es por el medio.

de ideación por parte del lector. Consecuentemente, cuando los esquemas y las perspectivas son vinculadas, los blancos 'desaparecen"' (183).

$24 \quad$ Esta tesis se acerca a la polaridad entre escritura y voz desarrollada por Michel de Certeau en varios de sus escritos. Si bien Certeau se centra particularmente en la escritura de la historia, algunas nociones de su pensamiento se ajustan a nuestra concepción de la escritura literaria. La escritura, sostiene Certeau, intenta calmar a los muertos y ocultar su alteridad en la trama del sentido. Los muertos, el pasado, son lo otro, lo ausente. La escritura, por eso mismo, es una tumba para los difuntos. En la trama de esta escritura, de este texto, una sociedad crea su propia identidad, se produce como legibilidad a partir de un corte o una grieta entre el presente y el pasado. El historiador, sostiene el teólogo y jesuita francés, realiza una distinción entre el pasado y el presente, permitiendo al presente diferenciarse del pasado y construirse como identidad. A través de la producción del pasado, se obtiene la producción del presente, es decir que el presente reconstruye al pasado, pero el pasado ejerce una influencia latente sobre tal reconstrucción (cf. Tarizzo 150). En esta demarcación, no obstante, algo queda olvidado, algo que, en cierta forma, debe dejar un lugar vacío para que una nueva identidad pueda constituirse. Este resto, o, como lo llama Certeau, este "otro", sin embargo, retorna permanentemente y se insinúa "...en las orillas y en las fallas del discurso" (Certeau 18). Es preciso indicar, de todos modos, que junto a la historia, el discurso literario, tanto narrativo como poético, se constituye en un espacio privilegiado para que las voces de los muertos, de los ausentes, se vuelvan audibles y puedan finalmente ser escuchadas. Allí donde la historia calla prudentemente, la literatura retoma la palabra y redobla la apuesta. El mismo Certeau, citando a Sade, se encarga de señalarlo: “...el buril de la historia sólo pinta al hombre cuando se deja ver y entonces ya no es el mismo, $[\ldots]$ el pincel de la novela, por el contrario, lo capta en su interior... lo toma cuando se quita la máscara" (Certeau 301). Esta alteridad, que Certeau identifica con el muerto, el otro, el ausente, designa justamente, en nuestra perspectiva, lo virtual, la scriptio inferior, el texto que, coexistiendo sin embargo con la scriptio superior, no puede nunca hacerse presente bajo el modo de la representación. 
Y aunque sólo haya dos términos, hay un $\mathrm{Y}$ entre los dos, que no es ni uno ni otro, ni uno que deviene el otro, sino que constituye precisamente la multiplicidad. Por eso siempre es posible deshacer los dualismos desde dentro, trazando la línea de fuga que pasa entre los dos términos o los dos conjuntos, estrecho arroyo que no pertenece ni a uno ni a otro, sino que los arrastra a los dos en una evolución no paralela, en un devenir heterócrono (Deleuze y Parnet 43).

La lectura literaria atañe especialmente a esta "Y" que se instaura entre el codex antiquior y el codex recentior, entre el texto virtual y el texto actual. Leer literariamente significa seguir (y al mismo tiempo trazar) la línea delgada que se instaura entre la scriptio inferior y la scriptio superior; significa recorrer el estrecho arroyo que no pertenece ni al texto visible ni al invisible; dejarse llevar, en una evolución a-paralela, por el ritmo de las fuerzas que oscilan entre ambas escrituras. Esta oscilación, hemos también señalado retomando una idea de Matière et mémoire, concierne de manera esencial a la imaginación. El vínculo entre la lectura literaria y la imaginación es, por eso mismo, también esencial ${ }^{25}$.

Según Wolfgang Iser, el lugar propio de la obra de arte literaria se encuentra entre el texto y el lector. Iser, además, denomina a ese espacio intermedio "posición virtual [virtual position]" (The Act of Reading 21). El proceso de lectura, el proceso a través del cual se concretiza el sentido de una obra literaria se caracteriza, para Iser, por una polaridad esencial: de un lado, el texto escrito por el autor (polo artístico); del otro, el lector que actualiza el texto (polo estético).

En función de esta polaridad, es claro que la obra misma no puede ser idéntica al texto o a la concretización, sino que debe ser situada en algún lugar entre los dos. Debe ser inevitablemente virtual en carácter, en la medida en que no puede ser reducida a la realidad del texto o a la subjetividad del lector, y es de esta virtualidad de dónde deriva su dinamismo (Iser 21).

Como resulta evidente, Iser considera que los dos polos que constituyen la tensión propia de toda obra literaria se identifican con la figura del autor y del lector. Según nuestro enfoque, esta distinción de Iser descansa sobre dos polaridades previas: una polaridad interna al texto (scriptio inferior y scriptio superior); otra interna al lector (la percepción presente y el recuerdo pasado, la materia y el espíritu -para decirlo en términos bergsonianos). Por eso Iser puede llamar virtual al espacio que se abre entre el texto y el lector, mientras que nosotros reservamos ese término para referirnos al texto invisible, al codex recentior ${ }^{26}$. Esta virtualidad existe también, lo hemos visto a partir de Bergson,

25

La explicitación exhaustiva de esta relación, que juzgamos fundamental, entre la lectura literaria y la imaginación excede las pretensiones de este artículo. Sin embargo, como señalamos en la nota 22, los análisis de Iser, particularmente en The Act of Reading, resultan fundamentales en esta perspectiva.

26 Es verdad que Iser reconoce que en toda obra literaria existe un texto formulado y un texto no formulado. Este texto no formulado consiste en "repertorios" (el mundo familiar extratextual aludido en el texto) y "estrategias" (en el caso de la novela: narrador, personajes, 
en la subjetividad del lector: es la memoria, el recuerdo, el inconsciente. Lo importante es que la lectura se produce cuando el pliegue del lector, la imaginación, se fusiona con el pliegue del texto. La fusión de horizontes, en nuestra perspectiva, debe entenderse como un contacto entre dos límites: el límite psíquico del lector (la imaginación, que ocupa el espacio intermedio entre la sensibilidad y el entendimiento, según la filosofía kantiana, o entre la percepción y la memoria, según la filosofía bergsoniana); y el límite específico del texto (la línea inextensa que articula la scriptio inferior, el plano virtual, con la scriptio superior, el plano actual).

\section{CONCLUSIÓN}

En un ensayo titulado L'autore come gesto, Giorgio Agamben propone llamar gesto a “...lo que permanece inexpresivo en todo acto de expresión..." y, al mismo tiempo, a lo que "...vuelve posible la expresión en la medida misma en que instaura en ella un vacío central" (cfr. Profanazioni 11). Que el ensayo de Agamben no se refiera meramente al autor, es decir al escritor, sino que englobe también al lector, y que por lo tanto el gesto sea precisamente el centro vacío en el que el autor y el lector se ponen en juego, es evidente por la función determinante que desempeña el concepto de gesto en lo que concierne a la lectura. "Él [el autor como gesto] es lo ilegible que vuelve posible la lectura, el vacío legendario del cual proceden la escritura y el discurso" (Agamben 12). Nos interesa particularmente esta noción de gesto, entendido como aquello que, siendo invisible y ausente, hace posible la presencia del discurso, ya que nos permite pensar la relación entre las dos escrituras que constituyen las dos caras, actual y virtual, de todo texto literario. No nos centraremos tanto en la identificación del autor con la categoría de gesto, según la tesis central del ensayo de Agamben, cuanto más bien en su identificación con la scriptio inferior, es decir, con la escritura que se borra o raspa para volver posible la scriptio superior, la nueva escritura. $\mathrm{Si}$, de acuerdo a nuestra hipótesis, todo texto literario puede ser considerado un palimpsesto, es porque en él conviven dos planos diversos: uno que podríamos identificar con el discurso efectivo o con la palabra escrita, presente, actual; otro, virtual, que podríamos identificar con la noción de gesto, con aquello que

trama y lector ficticio) que constituyen estructuras o esquemas a partir de los cuales el lector concretiza el sentido (los sentidos, a decir verdad) del texto. Cfr., al respecto, The Act of Reading caps. 3 y 4. Nuestra categoría de texto virtual (scriptio inferior), sin embargo, si bien no excluye estos elementos señalados por Iser, no se identifica totalmente con ellos. El trasfondo bergsoniano sobre el cual se apoya nuestra propuesta teórica conduce a plantear, no tanto una fenomenología de la lectura cuanto una ontología del texto o, mejor aún, una fenomenología de la lectura que se apoya necesariamente sobre una ontología del texto. Así como Deleuze, comentando a Bergson, sostiene que recordar significa saltar en la ontología, saltar al Ser (memoria ontológica), asimismo leer significa, en cierto sentido, saltar también al ser del texto, experimentar la dimensión virtual (no representativa) insinuada en los límites del texto actual. 
no está presente, que no está dicho pero que, desde su ausencia irrepresentable, hace posible la escritura efectiva. La lectura literaria haría referencia, entonces, a estos dos registros inescindibles: la palabra, lo dicho, la presencia, lo representable; el gesto, lo no-dicho, la ausencia, lo irrepresentable ${ }^{27}$. Ahora bien, sería una tentación considerar que la lectura, la "verdadera" lectura literaria, consiste en develar el gesto, en hacer visible lo invisible, en decir lo no-dicho. Sería una tentación errónea e infructífera. Sería suponer, como por detrás del texto escrito, de la scriptio superior, un segundo texto más originario, fundamental, que contendría la verdad y el sentido de lo dicho. Sería convertir a la scriptio inferior en el fundamento negativo de la scriptio superior. El estatuto del gesto, por el contrario, es similar al del enunciado según Foucault: al mismo tiempo no visible y no oculto. Pero si leer, al menos en el sentido en que aquí lo consideramos, no concierne específicamente ni al texto visible ni al texto invisible, ni al codex antiquior ni al codex recentior, si cuando leemos no leemos ni la scriptio inferior ni la scriptio superior, ni a Cervantes ni a Menard, ¿qué leemos cuando leemos?

La lectura literaria alude, como dijimos, al intersticio entre ambos textos. Leer es abrir una fisura entre las dos escrituras, entre la palabra y el gesto, abrir un hiato entre el texto actual y el texto virtual para instalarse allí. Este movimiento intersticial de apertura, esta práctica del intervalo es por necesidad, como hemos visto, traumática ${ }^{28}$.

27 Existe una cercanía, aunque no una identidad, entre esta categoría de gesto, con la cual nosotros nos referimos al texto virtual, y la categoría de "horizonte de expectativas" propuesta por Jauss en la línea de Gadamer. En efecto, al dialogar el lector con la obra, dispone ya de un sistema de referencias o presupuestos acerca de ciertos aspectos del texto: género, forma, temática, etc. “¿De dónde le viene este conocimiento? -se pregunta Adolfo Sánchez Vázquez en el ensayo El cambio de paradigma (Hans Robert Jauss) - De las obras leídas con anterioridad. Así, pues, al aparecer una obra, la lee, disponiendo ya de un 'horizonte de expectativas' y, al leerla, la sitúa en ese horizonte que ya conoce" (38).

28 Es preciso aclarar que en este espacio intersticial que se abre entre ambos textos, la escritura y la lectura tienden a volverse indiscernibles. No porque escribir sea igual que leer, sino porque este hiato o pliegue que separa y a la vez articula la scriptio inferior y la scriptio superior funciona como un lugar de encuentro, una superficie sin espesor en la que el lector y el autor, el ojo que lee y la mano que escribe, acaso por un instante, comparten una misma experiencia. De ahí que tanto la escritura como la lectura sean del orden de lo traumático. En este punto, la experiencia de la lectura literaria se acerca al concepto de "experiencia pura" formulado por William James. La "experiencia pura [pure experience]" (cfr Essays in Radical Empiricism 12), sostiene James, hace referencia a un flujo vital previo a todo dualismo y a toda distinción sujeto/objeto. En el ensayo titulado The Thing and its Relations, por ejemplo, leemos: "Experiencia pura es el nombre que le doy a un flujo inmediato de vida el cual proporciona el material para nuestra posterior reflexión con categorías conceptuales" (49-50). Según James, este flujo de vida o esta experiencia pura designa un punto o lugar de intersección de dos procesos: uno que constituye un campo de conciencia, otro que constituye el contenido de lo representado por esa conciencia. Es importante destacar, como dijimos, que tal distinción entre conciencia y contenido remite a un único plano de experiencia, el cual puede considerarse desde dos perspectivas diferentes: la del sujeto y la del objeto. Por eso 
Leer es hacer experiencia de ese trauma que consiste en inmiscuirse en el pliegue, en el umbral en el que se juegan las tensiones y las fuerzas entre ambas escrituras ${ }^{29}$. Lo que se abre, entonces, es el espacio mismo de las fuerzas, la superficie de los acontecimientos que oscilan entre ambos registros ${ }^{30}$. Siempre que leemos hacemos la experiencia de una palabra que se desplaza hacia lo indecible, que tiende a hacerse gesto, y de un gesto que se desplaza hacia lo decible, que tiende a hacerse palabra.

Partíamos de la pregunta ¿qué significa leer un texto literario? Respondemos, ahora: significa demorarse en un espacio que no pertenece exclusivamente ni al orden de lo visible ni al orden de lo invisible, significa instalarse en un lugar que ni siquiera es un lugar, en un espacio que no es un espacio; significa recorrer el entretejido, el inter-texto, no ya para develar lo invisible, lo no-dicho ${ }^{31}$, sino para sondear el margen o la frontera

James puede sostener que tanto “...el conocedor como lo conocido son la misma porción de experiencia considerada bajo dos contextos diferentes..." (30). Según nuestra perspectiva, la lectura literaria puede ser comprendida a partir de este concepto de James. El lector y el texto leído, el sujeto y el objeto, remiten a un mismo tejido (¿texto?) de experiencia que se identifica con la vida misma. Por esta razón, identificar al autor y al lector como "estrategias textuales", tal como hace Eco en varios de sus textos (cfr., por ejemplo, Lector in fabula 87-89), ¿no supone concebirlos como dos vectores o variables de una misma experiencia textual? Sobre el concepto de experiencia pura como condición de posibilidad tanto del sujeto como del objeto, cfr. el primero de los ensayos contenidos en Essays in Radical Empiricism (1912) titulado Does 'Consciousness' Exist? Esta experiencia compartida, además, puede ser asimilada, aunque desde otra óptica, a la "fusión de horizontes" planteada por Hans Georg Gadamer en Verdad y método, y retomada posteriormente por Hans Jauss.

29 En este sentido, la experiencia de la lectura, la lectura como experiencia, supone una puesta en juego radical de la vida en su totalidad, tan radical como la experiencia de escritura. No se trata, por supuesto, de un mero proceso intelectual, sino de una experiencia corporal decisiva que incluye, en cuanto tal, procesos intelectuales y emocionales. En la introducción a la Historia de la lectura, Roger Chartier escribe unas palabras que sintetizan de algún modo esta experiencia esencial: "La lectura no es solamente una operación intelectual abstracta: es una puesta a prueba del cuerpo, la inscripción en un espacio, la relación consigo mismo o con los demás" (19).

$30 \quad$ Este espacio oscilatorio, hemos sugerido, es propio de la imaginación. En la Kritik der reinen Vernunft, por ejemplo, se vuelve evidente este lugar intermedio que ocupa la imaginación. Para Kant (aunque se trata en verdad de un aspecto inherente a la historia de la filosofía), la imaginación funciona como el nexo entre la sensibilidad y el entendimiento. A través del esquematismo, la imaginación conecta las intuiciones con los conceptos para que sea posible el conocimiento (cfr. Kant 196-205).

31 En Lector in fabula, Umberto Eco alude a esta dimensión no dicha de un texto como un elemento indispensable para la concreción del sentido implícita en toda lectura literaria. "No dicho' significa no manifiesto en la superficie, en el plano de la expresión: pero precisamente son esos elementos no dichos los que deben concretizarse en la etapa de la actualización del contenido. Para ello, un texto (...) requiere ciertos movimientos cooperativos, activos y conscientes, por parte del lector" (74). 
en la que lo no dicho y lo dicho, lo virtual y lo actual, alcanzan su punto de mayor tensión y a la vez de mayor proximidad ${ }^{32}$. Por eso los autores que más nos fascinan, sin

32 Julia Kristeva, en Le sujet en procès, sostiene que el “...lenguaje como práctica social supone siempre dos modalidades, que no obstante se combinan de manera diferente para constituir diversos tipos de discursos, diversos tipos de prácticas significantes" (159-160). Kristeva identifica a estas dos modalidades del lenguaje con lo simbólico y lo semiótico. El extremo simbólico del lenguaje estaría representado por los discursos científicos, mientras que el extremo semiótico lo estaría por los discursos literarios, sobre todo poéticos (Céline, Artaud, Mallarmé, Lautréamont, etc.). Es posible identificar, en este sentido, a lo simbólico de Kristeva con la scriptio superior, el codex recentior, es decir la dimensión actual del texto, y a lo semiótico con la scriptio inferior, el codex antiquior, es decir la dimensión virtual. De tal manera que sería en la literatura donde el gesto, lo virtual, encontraría un espacio ( $s u$ espacio) de enunciación y de pronunciamiento. 'En relación con el 'espacio plano' de un sistema, la narrativización crea un 'espesor' que permite colocar, junto al sistema, a su contrario o a su resto" (La escritura de la historia 104). Estas palabras de Certeau, empleadas para definir lo propio de la historiografía, resultan aún más pertinentes, a partir de la distinción esbozada por Kristeva, para pensar la escritura literaria. A una idea similar parece llegar Umberto Eco cuando, comentando el libro Obra abierta, sostiene que la "apertura" de la obra literaria es el caso extremo de una característica propia de los textos en general. Basándose, al igual que Kristeva, en algunos análisis de Jakobson, Eco escribe: "Los textos que en aquél momento definía como 'abiertos' son sólo el ejemplo más provocativo de explotación con fines estéticos de un principio que regula tanto la generación como la interpretación de todo tipo de texto" (Lector in fabula 16). En efecto, en Obra abierta, Eco entendía por apertura la serie prácticamente infinita de significados contenida en un texto literario. Lo propio de la apertura que caracteriza a los textos literarios es la ambigüedad. "La característica del mensaje poético consiste en poseer una ambigüedad de estructura que, estimulando interpretaciones múltiples, obliga a fijar la atención en su propia estructura" (Apocalípticos e integrados 109; cfr. también Jakobson 30 , 218). En esta concepción de la obra literaria, el rol del lector es, por supuesto, fundamental: “...el lector del texto sabe que cada frase, cada figura, está abierta sobre una serie multiforme de significados que él debe descubrir..." (Obra abierta 34). En este sentido, lo propio de la lectura literaria consistiría, desde nuestra perspectiva, en mantener viva la tensión entre ambos textos, el actual y el virtual, la scriptio inferior y la scriptio superior. Y así como Kristeva sostiene que en los textos literarios, en especial los poéticos de vanguardia, el aspecto semiótico prima sobre el simbólico, asimismo podemos sostener que en los textos literarios el aspecto virtual se insinúa con mayor fuerza en la trama del texto actual, es decir que el texto actual y el virtual alcanzan un grado extremo de tensión. Lo propio de la lectura literaria, por esa razón, se encontraría en la actualización, no ya meramente del texto virtual, según la perspectiva adoptada en general por la estética de la recepción, sino del pliegue o del inter-texto, es decir del límite topológico en el que lo actual y lo virtual se fusionan, manteniendo sin embargo su heterogeneidad específica. No se trataría en consecuencia tanto de una fusión del horizonte presente del lector con el horizonte pasado del autor, sino más bien de dos fusiones: la fusión del horizonte presente del lector con la fusión de las dos dimensiones, actual y virtual, del texto literario. El lector actualiza una fusión textual, fusiona una fusión, la cual solo puede acontecer, no obstante, una vez que el texto es leído, es decir en el proceso de lectura. 
duda, son aquellos en los que ambas escrituras, ambos registros, presentan las máximas diferencias, llegando incluso a contraponerse. Lo decisivo, en todo caso, es esa superficie de encuentro, ese intersticio escritural. No hay lectura literaria que no aluda, directa o indirectamente, a ese margen que se instaura entre el texto visible y el texto invisible, entre lo actual y lo virtual, entre la vida y la muerte. La lectura literaria, en suma, es la experiencia del Tiempo ${ }^{33}$.

\section{BIBLIOGRAFÍA}

Agamben, Giorgio. Profanaziani. Roma: Nottetempo, 2005.

Andina, Tiziana. Arthur Danto: un filosofo pop. Roma: Carocci, 2010.

Bergson, Henri. Matière et mémoire. Essai sur la relation du corps à l'esprit. Paris: P.U.F., 1939.

Borges, Jorge Luis. Ficciones (1944). Obras completas. Buenos Aires: Emecé, 1987.

Chartier, Roger y Guglielmo Cavallo (eds.). Historia de la lectura en el mundo occidental. Madrid: Taurus, 2004.

Chartier, Roger. Inscribir y borrar. Cultura escrita y literatura (siglos XI-XVIII). Buenos Aires: Katz, 2006. La historia o la lectura del tiempo. Barcelona: Gedisa, 2007. La main de l'auteur et l'esprit de l'imprimeur. Paris: Gallimard, 2015.

Crisci, Edoardo. "Codices Graeci Rescripti fra Antichità e Medioevo bizantino. Il caso di palinsesti di Grottaferrata”. El palimpsesto grecolatino como fenómeno librario y textual. Coord. Ángel Escobar. Zaragoza: Institución "Fernando el Católico", 2006.

Danto, Arthur. The Transfiguration of the Commonplace. A Philosophy of Art. Londres: Hardvard University Press, 1981.

De Certeau, Michel. La escritura de la historia. México: Universidad Iberoamericana. Traducido por Jorge López Moctezuma, 2006.

Deleuze, Gilles y Claire Parnet. Dialogues. Paris: Flammarion, 1977.

Deleuze, Gilles. Différence et répétiton. Paris: P.U.F., 1968.

Le bergsonisme. Paris: P.U.F., 1966.

Eco, Umberto. Apocalípticos e integrados. Barcelona: Tusquets, 1995.

Lector in fabula. La cooperación interpretativa en el texto narrativo. Barcelona: Lumen, 1993.

Obra abierta. Barcelona: Planeta-Agostini, 1992.

33 Esta última frase alude implícitamente al título del ensayo de Roger Chartier $\mathrm{La}$ historia o la lectura del tiempo citado en la bibliografía. 
Escobar, Ángel. "El palimpsesto grecolatino como fenómeno librario y textual: una introducción". El palimpsesto grecolatino como fenómeno librario y textual. Coord. Ángel Escobar. Zaragoza: Institución "Fernando el Católico", 2006.

Foucault, Michel. Naissance de la clinique. Une archeologie du regard medical. Paris: P.U.F., 1963.

Gadamer, Hans-Gerog. Verdad y método. Salamanca: Ediciones Sígueme, Vol. I, 1996.

Genette, Gérard. Palimpsestes. La littérature au second degré. Paris: Seuil, 1962. Edición castellana: Palimpsestos. La literatura en segundo grado. Madrid: Taurus, 1989. Traducido por Celia Fernández Prieto.

Holub, Robert. "Reception theory: School of Constance". The Cambridge History of Literary Criticism, Volume 8: From Formalism to Poststructuralism, Cambridge University Press, 1995, pp. 319-346.

Iser, Wolfgang. The Act of Reading. A Theory of Aesthetic Response. London: John Hopkins University Press, 1980.

Jakobson, Roman. Essais de linguistique générale. Paris: Éditions de Minuit, 1963.

James, William. Essays in Radical Empiricism. New York: Longmans, Green \& Co., 1912.

Jauss, Hans Robert. Experiencia estética y hermenéutica literaria. Ensayos en el campo de la experiencia estética. Madrid: Taurus, 1986.

Jauss, Hans Robert. Pour une esthétique de la réception. Paris: Gallimard, 1978.

Kant, Immanuel. Kritk der reinen Vernunft. Würzburg: Felix Meiner, 1956.

Kristeva, Julia. "Le sujet en procès". Polylogue. Paris: Éditions du Seuil, 1977.

Lowe, Elias Avery. Palaeographical Papers 1907-1965. Oxford: Clarendon, Vol. II, 1972.

Merleau-Ponty, Maurice. Le visible et l'invisible. Paris: Gallimard, 1964.

Mukarovsky, Jan. Escritos sobre estética e semiótica da arte. Lisboa: Stampa, 1988.

Parmentier, Alix. La philosophie de Whitehead et le problème de Dieu. Paris: Beauchesne, 1968.

Sánchez Ortiz de Urbina, Ricardo. "La recepción de la obra de arte". Historia de las ideas estéticas y de las teorías artísticas contemporáneas. Ed. Valeriano Bozal. Madrid: Visor, Vol. II, pp. 213-228.

Sánchez Vázquez, Adolfo. "El cambio de paradigma (Hans Robert Jauss)". La Estética de la Recepción (I). México: Universidad Nacional Autónoma de México, Facultad de Filosofía y Letras, 2004.

Starobinsky, Jean. "Préface". Pour une esthétique de la réception. Paris: Gallimard, 1978.

Tarizzo, Davide. Il pensiero libero. La filosofía francese dopo lo strutturalismo. Milano: Raffaello Cortina Editore, 2003.

Válery, Paul. "Première leçon du cours de poétique". Variété V, Paris: Gallimard, 1944.

Warning, Rainer (ed.). Estética de la recepción. Madrid: Visor, 1989.

Whitehead, Alfred North. Process and Reality. An essay in Cosmology. New York: Macmillan Publishing Co., 1978. 